\title{
Migração transfronteiriça na Venezuela
}

\author{
FRANCILENE RODRIGUES
}

\section{Introdução}

$\mathrm{O}$ FENÔMENO MIGRATÓRIO internacional atual vem se caracterizando pelo desenvolvimento e constituição de sociedades em redes. A evolução dos transportes aumentou o volume e os movimentos desses deslocamentos e trouxe à tona a porosidade das fronteiras nacionais, étnico-culturais e identitárias, uma vez que nos terrenos das trocas materiais e simbólicas se confrontam indivíduos e culturas muito diferentes.

Dessa forma, as práticas de deslocamento devem ser percebidas como constitutivas de significados culturais em lugar de serem apenas uma extensão ou transferência desses significados. As redes sociais construídas na migração têm a capacidade de produzir modos de organização que ultrapassam as fronteiras de um Estado, de um território definido por uma linha geopolítica ou dois lados separados e vigiados arbitrariamente, mas também ligados por práticas legais e ilegais de cruzamentos, trocas e comunicações (Clifford, 1999, p.13).

O espaço fronteiriço entre o Brasil e a Venezuela também vem sendo profundamente impactado em virtude das novas tecnologias de transporte e comunicação intensificando os fluxos transfronteiriços de mercadorias (legais e ilegais), de pessoas (turistas, moradores de fronteiras, imigrantes, trabalhadores migrantes), bem como fluxos imateriais e simbólicos (bilingüismo, portunhol) em que as culturas e as identidades transcendem seu lugar de origem e se hibridizam a ponto de ser cada vez mais difícil identificar suas origens.

As zonas fronteiriças são zonas de empréstimos e apropriações culturais e, por isso, um lugar privilegiado para a compreensão do fenômeno migratório internacional. Essas fronteiras tanto podem se configurar como lugar de controle como de transgressão, seja das fronteiras geopolíticas seja das fronteiras culturais e da subjetividade.

O objetivo deste trabalho é apresentar alguns aspectos do processo de deslocamentos transfronteiriços ${ }^{1}$ no norte do Brasil, no município de Pacaraima (Estado de Roraima), e fronteira sul da Venezuela, no município Gran Sabana (Estado Bolívar), e indicar as tendências e reflexos nas configurações e reconfigurações socioculturais nessas zonas de contato.

Estudar essa região fronteiriça Brasil-Venezuela se justifica por ser a fronteira um lugar singular de trânsito, mas também de encontros culturais e de jogos de identidades. Essa percepção da fronteira como lugar de contato remete 
à idéia de movimento e de trocas, o que permite uma compreensão das dinâmicas das migrações sul-americanas e do processo de integração entre essas duas nações. Outro aspecto é o fato de não existir um levantamento empírico sobre a realidade migratória internacional que vem se modificando com a imigração de outras nacionalidades, tais como peruanos e bolivianos.

Este texto se divide em três partes. A primeira apresenta uma contextualização da tendência das migrações internacionais nos dois países limítrofes e o panorama dos movimentos de migração interna que convergem na migração internacional fronteiriça. A segunda descreve aspectos pertinentes à realidade migratória nessa transfronteira e algumas considerações sobre as configurações socioculturais decorrentes desse processo de deslocamento. A terceira contém algumas indicações e considerações finais.

\section{Processos de deslocamentos internacionais no Brasil e na Venezuela}

Entre o início do século XIX e meados do XX, América Latina e Caribe foram cenários de intensa imigração desde a Europa. Porém, esse quadro tem se modificado em decorrência de fatores econômicos e sociopolíticos ocorridos no continente, bem como do processo de globalização. Segundo a Cepal, vinte milhões de latino-americanos e caribenhos vivem fora de seus países. Dentre as tendências dessas migrações internacionais, observam-se deslocamentos significativos dentro da própria América Latina e, predominantemente, entre os países fronteiriços.

O Brasil e a Venezuela vivenciaram diversas fases como países receptores de migrantes. O Brasil funcionou como país receptor de imigrantes até a década de 1960, para, a partir daí, passar a exportar mão-de-obra principalmente para os Estados Unidos, alguns países da Europa e para o Japão, dentro de um novo contexto social, político e cultural (Patarra \& Baeninger, 1996).

A Venezuela alternou esse papel de receptor nas décadas de 1950 e de 1970 a 1990, com uma redução de imigração internacional nos anos 1960. Os estrangeiros em 1950 representavam 4,1\% da população total da Venezuela. Em 1971, representavam 5,5\%. Em 1980, eram 7,4\%. Em 1990, totalizavam 5,7\% dos imigrantes e, desses, 70\% eram oriundos da América Latina e do Caribe, em especial da Colômbia, representando $51,7 \%$ do total de estrangeiros, seguidos de peruanos, equatorianos, bolivianos, dominicanos, guianenses e haitianos (Sarmento, 2000, p.30). Nessa mesma década, os brasileiros representavam apenas $0,63 \%$ dos latinos americanos e $0,41 \%$ do total de estrangeiros na Venezuela (Baeningen, 2002). Pode-se afirmar que, de uma maneira geral, a Venezuela não é o destino prioritário para os emigrantes brasileiros que preferem Paraguai, Uruguai, Argentina, Guiana Francesa, Suriname, Bolívia.

Esse quadro se modifica na fronteira entre Brasil e Venezuela, tendo em vista que a emigração fronteiriça é uma possibilidade viável de ascensão social para o grande contingente de migrantes interestaduais e, também, pelas con- 
dições de proximidade e facilidade de acesso via terrestre. Vale lembrar que a capital da unidade da federação mais próxima a Boa Vista, Manaus, fica a quase oitocentos quilômetros de distância, enquanto a fronteira com a Venezuela fica a menos de duzentos quilômetros.

Para melhor compreender os processos de migração nessa fronteira Brasil-Venezuela, torna-se fundamental indicar os processos de migração vividos por esses migrantes dentro de seu próprio país até se estabelecerem nos países vizinhos.

\section{As fronteiras de expansão no Brasil e na Venezuela}

As fronteiras internas não estão marcadas por limites e divisas físicas, mas sim imaginárias. Não há uma definição precisa de onde começa e onde termina a fronteira interna. As fronteiras internas são áreas de expansão onde a ordem econômica e social da nação deve ainda ser implantada. Desse modo, podemos afirmar que tanto a região Guayana na Venezuela quanto a região Amazônica ${ }^{2}$ são consideradas fronteiras internas de suas nações.

O Estado Bolívar ao sul da Venezuela e o Estado de Roraima na Região Norte do Brasil possuem similitudes, tais como o fato de se constituírem em grandes espaços em relação aos seus respectivos territórios nacionais; ${ }^{3}$ viverem processos de expansão da fronteira econômica, cujos programas oficiais de exploração de recursos naturais enfatizavam o caráter de "espaços vazios”, culminando com políticas de ocupação baseadas no conceito de desenvolvimento vinculado à doutrina de Segurança Nacional; são palcos de constantes conflitos pelo controle dos recursos naturais travados por diversos atores sociais (índios, garimpeiros, madeireiros, empresários, fazendeiros, militares); possuem populações indígenas significativas e estão situados em áreas de fronteira internacional; portanto, em área que delimita a soberania das duas nações.

A diferença visível entre esses estados é que Bolívar é um grande centro de indústrias de bases, enquanto Roraima sobrevive predominantemente dos recursos federais e de um setor primário incipiente. Todavia, os dois estados funcionam como lugares de atração populacional regional cujas taxas de migração intra-regional são altas, conforme o Quadro 1. O crescimento populacional foi significativo para o Estado Bolívar nas décadas de 1960 e 1970, e para o Estado de Roraima nas décadas de 1980 e 1990. O movimento imigratório dos anos 1990, em Roraima, conciliou os atrativos da "fronteira agrícola" com a "frente garimpeira". "A atividade de mineração se configurou, durante toda a década de 1980 e início da de 1990, no principal atrativo à migração. Já para o Estado Bolívar, o movimento imigratório foi favorecido, dentre outros fatores, pelo processo de instalação de projetos de infra-estrutura e indústrias básicas de siderurgia e energia.

Os municípios fronteiriços de Gran Sabana e Pacaraima apresentam características muito similares quanto a inserção regional e ocupação dos territórios estaduais e nacionais. São munícipios de projetos de expansão agrícola, áreas 
de intensa exploração mineral ao longo de suas histórias, e possuem um grande contingente de população indígena.

Quadro l - População residente. Roraima e Bolívar - 1950/2000

\begin{tabular}{c|c|c|c|c}
\hline \multirow{2}{*}{ ANOS } & \multicolumn{2}{c|}{ Estado de Roraima } & \multicolumn{2}{c}{ Estado Bolívar } \\
\cline { 2 - 5 } & $\begin{array}{c}\text { População } \\
\text { absoluta }\end{array}$ & $\begin{array}{c}\text { Cresc. (\%) } \\
\text { década }\end{array}$ & $\begin{array}{c}\text { População } \\
\text { absoluta }\end{array}$ & $\begin{array}{c}\text { Cresc. (\%) } \\
\text { década }\end{array}$ \\
\hline $\mathbf{1 9 5 0}$ & 18.116 & & 127.436 & 34,8 \\
\hline $\mathbf{1 9 6 0}$ & 28.304 & 56,1 & 213.543 & 67,6 \\
\hline $\mathbf{1 9 7 0}$ & 40.885 & 44,4 & 391.665 & 83,4 \\
\hline $\mathbf{1 9 8 0}$ & 79.159 & 93,6 & 668.340 & 70,6 \\
\hline $\mathbf{1 9 9 1}$ & 217.583 & 174,8 & 900.310 & 34,7 \\
\hline $\mathbf{2 0 0 0}$ & 324.152 & 48,9 & 1.214 .846 & 34,9 \\
\hline
\end{tabular}

Fontes: IBGE; Elaboração AT\&M (Fecor, 1995, p.13). OCEI. Censos 1961 a 2000.

Santa Elena está mais distante da capital do Estado Bolívar $(700 \mathrm{~km})$ que Pacaraima $(215 \mathrm{~km})$. Santa Elena e Pacaraima são municípios de baixa densidade demográfica e uma população flutuante representativa tanto de nacionais como de estrangeiros. Pacaraima não se configura como um atrativo para os imigrantes no Estado, em um primeiro momento, embora represente o oitavo município em relação à população, ficando à frente de municípios localizados nas regiões de expansão da fronteira agrícola ao sul do Estado. O fluxo migratório em Pacaraima intensificou-se em virtude da perspectiva de criação de uma Área de Livre-Comércio e da criação do município em 1997 e com as freqüentes oscilações econômicas enfrentadas pelos países limítrofes Brasil-Venezuela, o que possibilita a ascensão econômica de um, quando o outro baixa. Lembrando que no final da década de 1980 eram os moradores da cidade de Boa Vista que cruzavam a fronteira com a Venezuela para lá adquirir bens, abastecer o carro e, eventualmente, seus estabelecimentos comerciais.

Hoje, os venezuelanos também transitam freneticamente nessa fronteira com vistas à aquisição de bens e utilização de serviços, como o de saúde e educação. Dessa forma, vários comerciantes, em maioria cearense, abriram filiais de suas matrizes de Boa Vista em Pacaraima, onde conseguiram retomar o aquecimento da economia do Estado. Portanto, esse crescimento econômico influenciou o processo migratório para Pacaraima e depois para Santa Elena do Uairén.

Do outro lado da fronteira brasileira, está Santa Elena de Uairén, capital da Gran Sabana. Há em torno da cidade acampamentos e povoados genuinamente mineiros. A economia de Santa Elena gira em torno da atividade de garimpagem nas minas que estão ao seu redor e atua como centro de comercialização e aprovisionamento dos garimpeiros e de suas famílias que residem em Santa Elena. Outro aspecto econômico da cidade é o comércio transfronteiriço dos habitantes de Pacaraima/Boa Vista e Santa Elena, além do turismo e dos empregos pú- 
blicos. Santa Elena possui uma infra-estrutura de diversão maior que Pacaraima, com boates, restaurantes, uma casa noturna de strip-tease-geralmente realizado por brasileiras - cafés e cyber cafés.

Quadro 2 - População residente Gran Sabana (Estado Bolívar) e Pacaraima (Estado de Roraima) - 1990-2000

\begin{tabular}{c|c|c|c|c}
\hline \multirow{2}{*}{ ANOS } & \multicolumn{2}{|c|}{ Pacaraima* $^{*}$} & \multicolumn{2}{c}{ Gran Sabana } \\
\cline { 2 - 5 } & \multicolumn{2}{|c|}{ Tx de Cresc. \% a.a } & \multicolumn{2}{c}{ Tx Cresc. \% a.a } \\
\hline 1990 & $5.777^{\star}$ & - & 16.235 & 1,8 \\
\hline 2000 & 6.990 & 4,88 & 9.220 & 0,8 \\
\hline
\end{tabular}

Fontes: IBGE; censo 2000. * Dados de 1996, quando foi criado o município. OCEI - INE. Censos 1961 a 2000.

Essa fronteira é identificada como uma das rotas para o tráfico de mulheres e adolescentes cujo eixo é Manaus (AM)-Iracema(RR)-Boa Vista(RR)Pacaraima(RR)-Santa Elena-Puerto Ordaz-Puerto La Cruz-Isla de Margarita-Caracas. Segundo o relatório Pesquisa sobre Tráfico de Mulheres (Pestraf) (2003), a Venezuela é receptora e lugar de passagem para outros centros, como República Dominicana e Europa.

\section{O deslocamento na transfronteira e a configuração social}

Esse lugar fronteiriço Pacaraima-Santa Elena do Uairén encerra uma caracterização de relações e movimentos de pessoas que transitam, deslocam-se e, conseqüentemente, definem o lugar a partir dos efeitos produzidos e conteúdos expressos, tanto nos aspectos da vida cultural quanto nos aspectos identitários que também se deslocam e se pluralizam (Hall, 2003). Esses sujeitos que vivem a e na fronteira podem ser classificados em categorias como fronteiriços, aqueles nascidos nessa zona de fronteira; os fronteiriços nacionais migrantes, que são os provenientes de outras regiões do país; e os fronteiriços internacionais migrantes, que incluem todos os estrangeiros (Marcano, 1996). Acrescentaria os viajantes, aqueles que fazem da fronteira um lugar de trânsito, de cruzamento diário por motivos laborais, de diversão e lazer (Clifford, 1999).

Uma das características desse movimento migratório fronteiriço é o trânsito de pessoas ilegais e indocumentadas. Para cruzar a fronteira, não é necessário passaporte, mas apenas um documento de identidade e o cartão de vacina. No caso da Venezuela, há uma ostensiva vigilância representada pelas alcabalas ao longo da rodovia transamericana que liga Santa Elena à costa e ao centro do país. No caso do Brasil, a fiscalização só é realizada em momentos específicos e esporádicos de alguma campanha contra o contrabando de combustível ou contra o tráfico de mulheres. Dessa forma, a facilidade de acesso via terrestre e a pouca fiscalização favorecem o fluxo de migrantes ilegais que cruzam a fronteira tanto para se estabelecerem um em Boa Vista e Pacaraima como em Santa Elena e outras cidades vizinhas na Venezuela. 


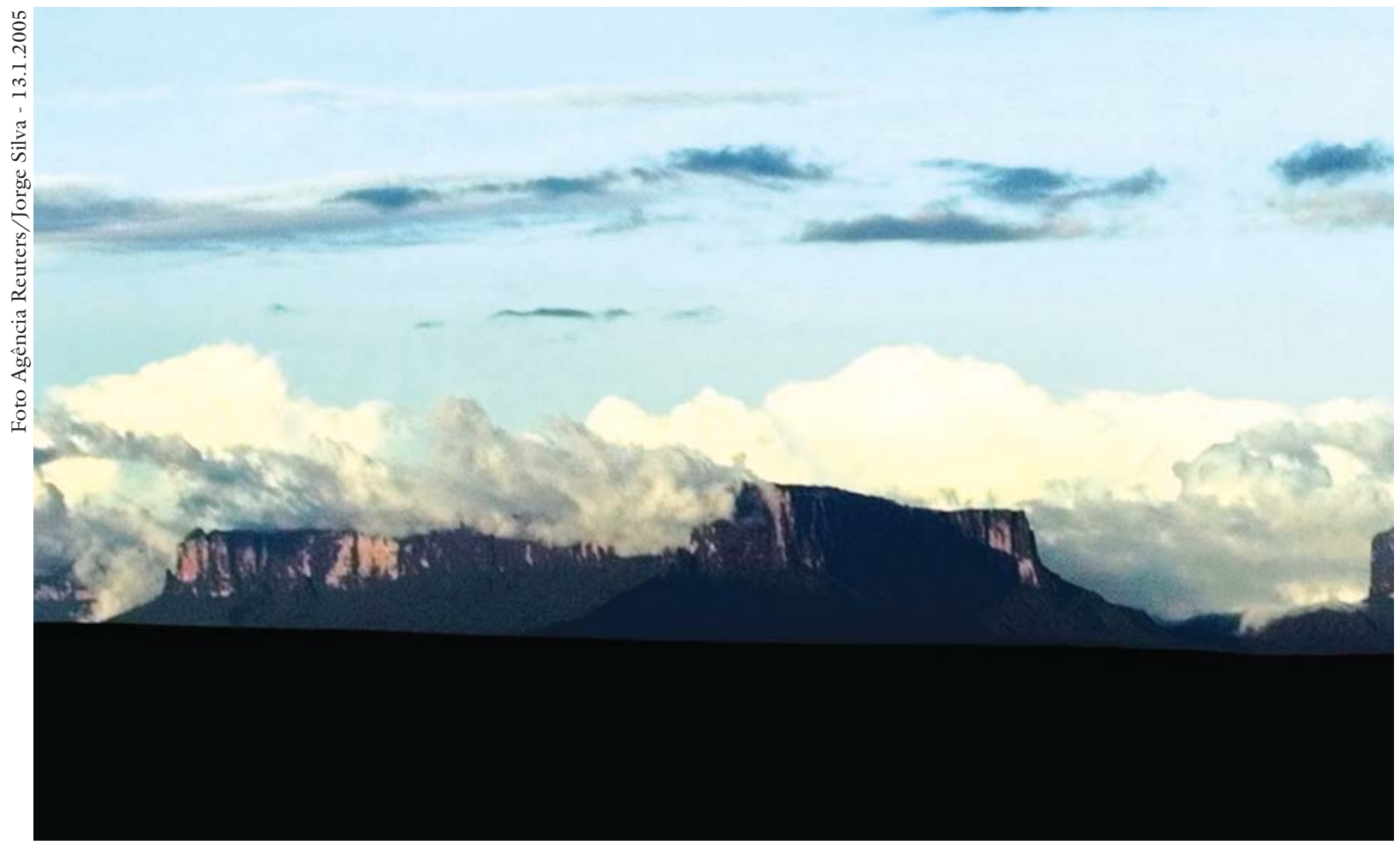

Vista do Monte Roraima, com 2.727 metros de altitude e relevo raro em forma de mesa, que

O fluxo de fronteiriços internacionais nessa fronteira é um fenômeno que pode ser percebido nas feiras, nos centros comerciais tanto de Santa Elena quanto de Boa Vista. Na feira livre de Santa Elena, que acontece às sextas-feiras, podem ser encontrados colombianos, "chinos", indígenas de diversas etnias, peruanos, bolivianos e brasileiros. Os guianenses têm a Venezuela como a terceira opção para emigração depois dos Estados Unidos e do Suriname. Na Venezuela, entram pelo Estado Bolívar e atuam nos setores de produção agrícola, madeireira, mineira e de serviços. Em 1995, as estimativas do Conselho Nacional de Fronteiras era que havia no Estado Bolívar em torno de sessenta mil ilegais no país, e que mais da metade desse total era formada de haitianos, colombianos, dominicanos, guianenses e brasileiros.

Os imigrantes guianenses mantêm colônias residenciais, igrejas e centros educativos privados; são considerados bons agricultores e detêm o monopólio da venda de sorvetes, malta e venda ambulante. Eles entram na Venezuela trazidos por uma determinada empresa fabricante de sorvetes. Em Santa Elena podem ser vistos vendendo picolés e no emprego doméstico

Segundo dados oficiais, os brasileiros emigram mais para a Venezuela do que os venezuelanos para o Brasil. Há mais brasileiros estabelecidos na Venezuela que o contrário. Esse movimento de brasileiros para a Venezuela, a partir de Roraima, teve dois momentos: o primeiro, em meados dos anos 1970, com o declínio da garimpagem de diamantes em Roraima e da estabilidade econômica na Venezuela - esse emigrantes brasileiros se estabeleceram no ramo do comér- 


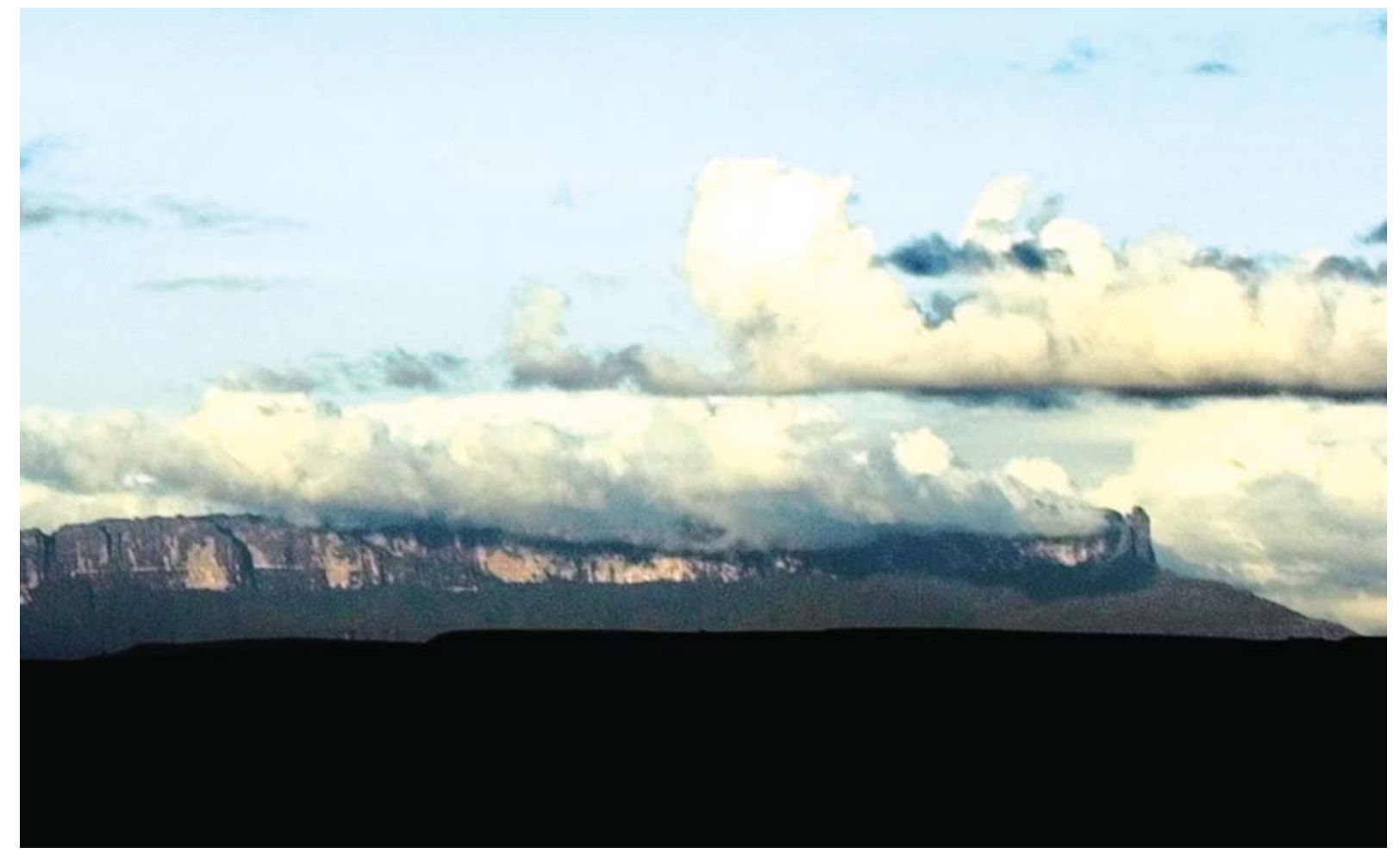

se formou há cerca de 2 bilhões de anos; é um dos mais antigos e exóticos lugares do planeta.

cio vinculado à mineração, como casas de compra e venda de ouro e diamantes, e se estabeleceram em Ciudad Bolívar e Santa Elena do Uairen -; o segundo, em fins dos anos 1980 e 1990, também com o declínio do boom garimpeiro no Brasil brasileiros emigraram para atuar ilegalmente na mineração na Venezuela, gerando várias crises diplomáticas entre os dois países.

O que caracteriza esse segundo movimento migratório é o alargamento da participação dos brasileiros em outros ramos da econômia de fronteira que pode ser identifcado a partir dos nomes dos estabelecimentos comerciais nos mais diversos ramos, tais como restaurantes, loja de confecção, venda de pneus e acessórios para carros, casa de câmbio, casa de compra e venda de ouro e diamantes. Os brasileiros podem ser encontrados no setor de serviços como vendedores em lojas, atendentes de lanchonetes geralmente de proprietários brasileiros, manicuras, depiladoras. Surgem também os migrantes laborais como as empregadas domésticas que vivem em Pacaraima e todo dia cruzam a fronteira para trabalhar em Santa Elena, os taxistas de táxi-lotação que transportam passageiros diariamente de Boa Vista para Pacaraima e Santa Elena e vice-versa, competindo com as linhas regulares de ônibus.

Em Boa Vista, os fronteiriços internacionais migrantes podem ser encontrados no mercado de trabalho informal, nas ruas dos camelôs, na feira do produtor. Os guianenses são os imigrantes internacionais de maior representativa em Roraima, principalmente a partir dos anos 1960, em decorrência da crise política e econômica daquele país. Outro fator que tornou a imigração guia- 


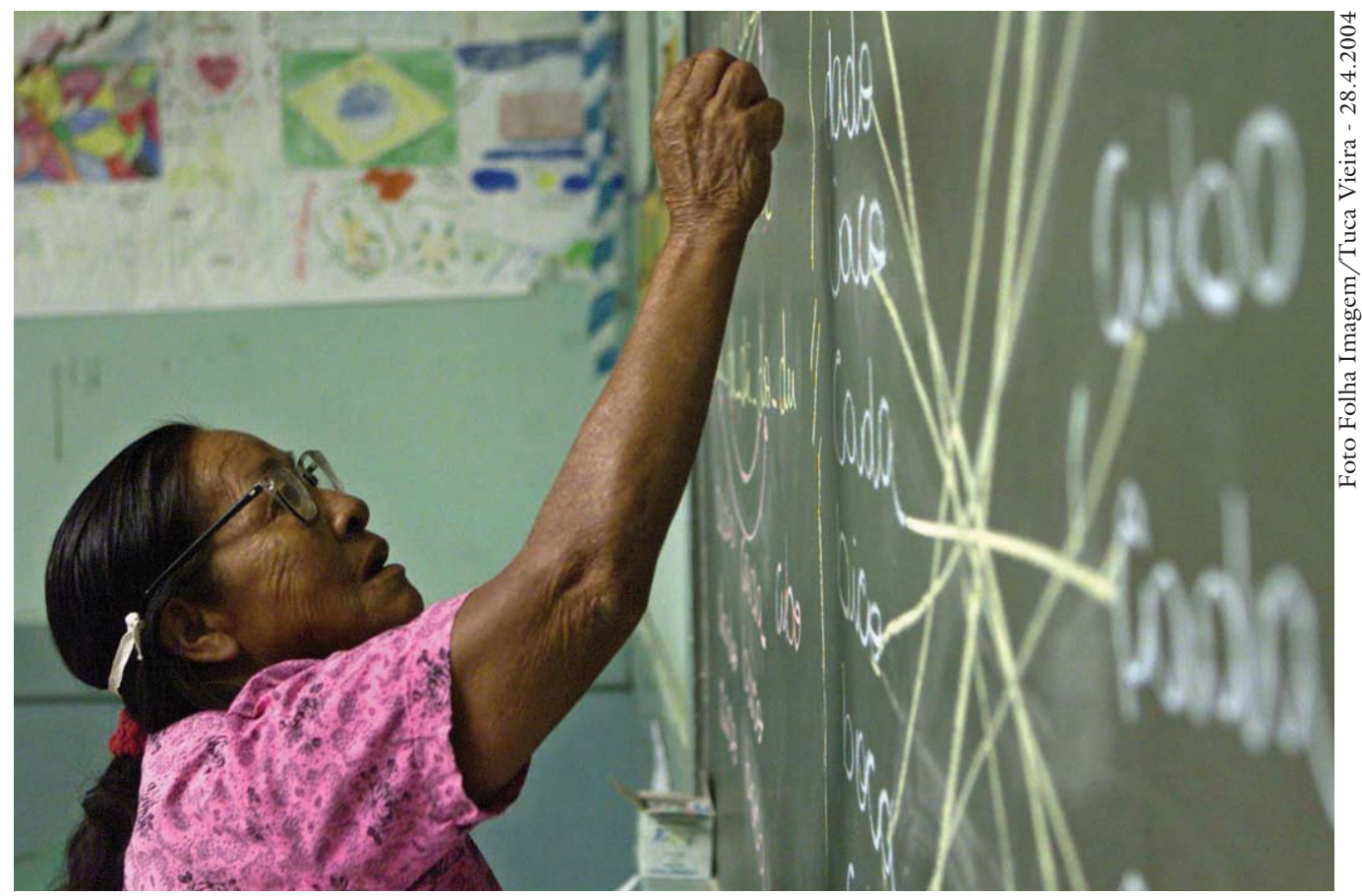

Programa de alfabetização ensina português e macuxi para a população de Uiramutã, $R R$.

nense mais significativa é o aspecto da existência de várias etnias que transitam entre o Brasil e a Guiana. Em 2001, o município fronteiriço de Bonfím tinha uma população de migrantes internacionais em torno de 3,4\% (Barcelos, 2001). Em Boa Vista, os guianenses estão presentes no mercado informal, no emprego doméstico e na construção civil.

Uma novidade atual na característica dos migrantes internacionais em Roraima é a identificação de colombianos e peruanos normalmente trabalhando como vendedores ambulantes de discos e produtos chineses. Não há dados oficiais, uma vez que a maioria vive em situação de clandestinidade e de ilegalidade. Daí a dificuldade em se fazer uma estimativa da presença quantitativa dos migrantes internacionais nessas fronteiras. Embora não haja elementos oficiais, podemos induzir que a entrada de imigrantes de outras nacionalidades no Estado de Roraima se dá por três vias ou três itinerários: o primeiro itinerário é pela fronteira Brasil-Guiana; o segundo, pela fronteira Brasil-Venezuela, seja de brasileiros e venezuelanos seja de peruanos e de colombianos; o terceiro itinerário é o de entradas de colombianos e peruanos a partir da tríplice fronteira PeruColômbia-Brasil, com entrada por Manaus. Todos esses itinerários são favorecidos pelas condições de transportes terrestres e pela quase ausência de controle durante o percurso.

\section{Considerações finais}

Os processos migratórios são complexos, e mais ainda as migrações transnacionais, por envolverem aspectos de fronteira nacional, soberania e processos de transculturação. Nessa fronteira Brasil-Venezuela, podemos afirmar que o 
trânsito maior é de brasileiros para a Venezuela e para a Guiana, em decorrência das possibilidades de atuarem nas atividades de mineração, no comércio local e no setor de transportes, além das atividades ilegais, como tráfico de mulheres, contrabando de combustível, câmbio ilegal de moeda. Já a imigração de transfronteiriços ainda é incipiente, com exceção dos imigrantes guianenses.

Apresenta-se, no entanto, uma tendência que é a imigração de estrangeiros de outros países do continente. Esses migrantes tranfronteiriços percorrem os países fronteiriços em itinerários cuja porta de entrada é a Venezuela, mas também o Estado do Amazonas. Pode-se inferir que, dentre outros fatores, a língua foi e ainda é um elemento restritivo para a imigração nessa fronteira; outro fator é o fato de Roraima não ser um Estado com economia atrativa. Essa migração não-oficial de transfronteiriços, mesmo não sendo muito significativa regionalmente, começa a ter certo impacto na configuração das comunidades locais de origem e destino.

Essa realidade dos migrantes transfronteiriços aponta para várias lacunas na política de migração brasileira, sustentada apenas nos interesses puramente econômicos e comerciais e, portanto, sem a perspectiva de uma integração sociocultural latino-americana. São vários os exemplos: dos trabalhadores que estabelecem o fluxo diário entre essas cidades sem nenhuma garantia trabalhista ou de cidadania; os conflitos recentes na fronteira Brasil-Venezuela decorrente das exigências dos seguros internacionais para a entrada de carros brasileiros na Venezuela ou da exigência do cartão de vacina para entrada no Brasil; do aumento do tráfico de mulheres, dentre outros. Para cada uma dessas ações, é seguida de reações e pressões sobre os estrangeiros que tentam cruzar a fronteira denotando uma falta de política específica para essas configurações socioculturais de fronteira.

A contagem populacional desse contingente migratório adentrando diariamente as fronteiras torna-se fundamental para a definição de medidas e políticas a serem tomadas conjuntamente como parte de um projeto maior que é o de integração da América do Sul, não apenas em âmbito econômico, mas também cultural e identitário.

Espero que este texto funcione como estímulo para o desenvolvimento de trabalhos mais aprofundados e que incentive a continuidade dos estudos sobre os processos migratórios nessa fronteira.

Notas

1 Refiro-me à transfronteira em seu sentido restrito, como territórios limitados e contíguos a uma determinada fronteira, ou seja, às zonas e regiões fronteiriças propriamente ditas.

2 Concebo Amazônia e Guayana como espaços e lugares de representações simbólicas e não apenas uma construção do ponto de vista geofísico, mas também cultural. Do ponto de vista político-administrativo, a região está conformada administrativamente 
pelos estados Bolívar, nos quais está inserida a Amazônia venezuelana, o território do Amazonas e o Delta Amacuro, além de 112 mil hectares dos estados Anzoátegui e Monagas. A Região Amazônica engloba os estados do Pará, do Amazonas, do Amapá, do Acre, da Rondônia e de Roraima.

3 O Estado Bolívar possui uma área territorial de 238 mil quilômetros, e o Estado de Roraima, 225.116 quilômetros, representando $26,24 \%$ e 2,64\% do território nacional, com densidade demográfica de $5,15 \%$ e $0,19 \%$, respectivamente. O Estado Bolívar e o Estado de Roraima possuem onze e quinze municípios, respectivamente.

4 Adotaremos o sentido proposto por Oliveira Filho (1979), que define fronteira como "um mecanismo de ocupação das novas terras e de sua incorporação, em condição subordinada, dentro de uma economia de mercado", e Pereira (1992), que trabalha com o conceito de "frente garimpeira", onde, para ele, essa frente se superpôs à frente agrícola da Amazônia na década de 1980.

Referências bibliográficas

ACOSTA, N.; JUNGEMANN, B. Transformación Territorial y gestión local: el caso de Ciudad Guayana. Cuadernos del CENDES, ano 17, n.43, p.121-54, enero-abril 2000.

BAENINGER, R. La migración internacional de los brasileños: características y tendencias. Santiago de Chile: Centro Latinoamericano y Caribeño de Demografía (Celade). División de Población y Desarrollo, mayo de 2002.

BARCELOS, C. et al. A geografia da AIDS nas fronteiras do Brasil. 2001. Disponível em: <http://www.igeo.ufrj.br|fronteiras\pdf>. Acesso em 25.5.2006.

CLIFFORD, J. Itinerários transculturales. Barcelona: Gedisa, 1999.

FECOR.Federação do Comércio de Roraima. Diagnóstico do Estado de Roraima. Boa Vista-RR: AT\&M, 1995.

HALL, S. Da Diáspora. Identidades e mediações culturais. Belo Horizonte: Editora da UFMG, 2003.

HILY, M.-A. As migrações contemporâneas: dos Estados e dos homens. In: Seminário Cultura e Intolerância. Sesc Vila Mariana. São Paulo, novembro de 2003.

MARCANO, E. E. J. La construccion de espacios sociales transfronterizos entre Santa Elena de Uairén(Venezueal) y Villa Pacaraima (Brasil). Brasilia, 1996. Tese (Doutorado em Sociología) - Facultad Latinoamericana de Ciencias Sociales, Flacso. Universidade de Brasília.

OLIVERA FILHO, J. P. . O caboclo e o brabo: notas sobre duas modalidades de força de trabalho na expansão da fronteira amazônica no século XIX. Rio de Janeiro: Encontros Com a Civilização Brasileira, 1979, v. 11.

PATARRA, N.; BAENINGER, R. Migrações internacionais recentes: o caso do Brasil. In: PATARRA, N. (Coord.) Emigração e imigração internacional no Brasil Contemporâneo. São Paulo: Fundo de Populações das Nações Unidas, 1996.

PEREIRA, A. C. L. Garimpo e fronteira amazônica: as transformações dos ano 80. In: LENA, P.; OLIVEIRA, A. (Orgs.) Amazônia: fronteira agrícola 20 anos depois. Belém: Cejup\MPEG, 1992. 
SARMENTO, G. S. Diagnóstico sobre las migraciones caribeñas hacia Venezuela. Buenos Aires: PLACMI-OIM, 2000.

RESUMO - AS ZONAS fronteiriças são zonas de empréstimos e apropriações culturais e, por isso, um lugar privilegiado para a compreensão do fenômeno migratório internacional. O objetivo deste trabalho é apresentar alguns aspectos do processo de deslocamentos transfronteiriços no norte do Brasil, no município de Pacaraima (Estado de Roraima) e na fronteira sul da Venezuela, no município de Gran Sabana (Estado Bolívar), e, ao mesmo tempo, apontar as tendências e reflexos nas configurações socioculturais nessas zonas de contato. Nessa fronteira Brasil-Venezuela, podemos afirmar que o trânsito maior é de brasileiros para a Venezuela e para a Guiana, em decorrência das possibilidades de atuarem nas atividades de mineração, no comércio local e no setor de transportes, além das atividades ilegais, como tráfico de mulheres, contrabando de combustível e câmbio ilegal de moeda. Apresenta-se, no entanto, uma nova tendência que é a imigração de estrangeiros de outros países do continente, tais como peruanos e colombianos. Esses migrantes transfronteiriços percorrem os países fronteiriços em itinerários cuja porta de entrada é a Venezuela e a Guiana, mas também o Estado do Amazonas.

PALAVRAS-CHAVE: Migração transfronteiriça, Fronteira Brasil-Venezuela, Configurações culturais.

ABSTRACT - BORDER zones are zones of cultural lending, borrowing and appropriation, and, therefore, a privileged vantage point for understanding the phenomenon of international migration. This essay attempts to examine certain aspects of the transborder dislocation process in northern Brazil (the city of Pacaraima, state of Roraima) and in southern Venezuela (the city of Gran Sabana, state of Bolívar), and point out its trends and reflections on the sociocultural makeup of those contact zones. In this Brazil-Venezuela border, the largest movement is clearly that of Brazilians going into Venezuela and Guyana in search of job opportunities in mining, local business and transportation, not to mention illegal activities such as the traffic of women, fuel smuggling and illicit money exchange. Yet a new trend is now emerging, namely, the immigration of foreigners from other South American countries, such as Peru and Colombia. These migrants cross over into neighboring countries following a route whose front door is Venezuela, Guyana and the Brazilian state of Amazonas.

KEYWORDS: Transborder migration, Brazil-Venezuela border, Cultural makeup.

Francilene Rodrigues é professora da Universidade Federal de Roraima e doutoranda do Programa de Pós-Graduação Sobre as Américas - Ceppac, da Universidade de Brasília (UnB). @ - francerodrigues@yahoo.com.br

Recebido em 29.5.2006 e aceito em 30.5.2006. 